\title{
Development of Novel Transparent Radiation Shielding Glasses by BaO Doping in Waste Soda Lime Silica (SLS) Glass
}

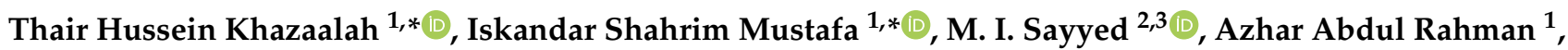 \\ Mohd Hafiz Mohd Zaid ${ }^{4}\left(\mathbb{D}\right.$, Rosdiyana Hisam ${ }^{5}$, Muhammad Fadhirul Izwan Abdul Malik ${ }^{6} \mathbb{D}, N^{1}$ asu Seth Ezra ${ }^{1}$, \\ Hayder Salah Naeem ${ }^{1}$ and Nuridayanti Che Khalib ${ }^{1}$
}

Citation: Khazaalah, T.H.; Mustafa, I.S.; Sayyed, M.I.; Abdul Rahman, A.; Mohd Zaid, M.H.; Hisam, R.; Izwan Abdul Malik, M.F.; Seth Ezra, N.; Salah Naeem, H.; Che Khalib, N. Development of Novel Transparent Radiation Shielding Glasses by $\mathrm{BaO}$ Doping in Waste Soda Lime Silica (SLS) Glass. Sustainability 2022, 14, 937. https://doi.org/10.3390/ su14020937

Academic Editor: Mengge Dong

Received: 17 December 2021

Accepted: 11 January 2022

Published: 14 January 2022

Publisher's Note: MDPI stays neutral with regard to jurisdictional claims in published maps and institutional affiliations.

Copyright: (C) 2022 by the authors. Licensee MDPI, Basel, Switzerland. This article is an open access article distributed under the terms and conditions of the Creative Commons Attribution (CC BY) license (https:// creativecommons.org/licenses/by/ $4.0 /)$
1 School of Physics, Universiti Sains Malaysia (USM), Gelugor 11800, Malaysia; azharar@usm.my (A.A.R.); 1982isseth@gmail.com (N.S.E.); hayder985@student.usm.my (H.S.N.); nuridayantichekhalib@gmail.com (N.C.K.)

2 Department of Physics, Faculty of Science, Isra University, Amman 11622, Jordan; mohammed.alsyyed@iu.edu.jo

3 Department of Nuclear Medicine Research, Institute for Research and Medical Consultations (IRMC), Imam Abdulrahman Bin Faisal University (IAU), Dammam 31441, Saudi Arabia

4 Department of Physics, Faculty of Science, Universiti Putra Malaysia, Serdang 43400, Malaysia; mhmzaid@upm.edu.my

5 Faculty of Applied Sciences, Universiti Teknologi MARA, Shah Alam 40450, Malaysia; rosdiyana@uitm.edu.my

6 Science and Engineering Research Center, USM Engineering Campus, Universiti Sains Malaysia, Nibong Tebal 14300, Malaysia; fadhirul@usm.my

* Correspondence: khazaalah@yahoo.com (T.H.K.); iskandarshah@usm.my (I.S.M.)

\begin{abstract}
In the current study, $\mathrm{BaO}$ was doped in $\mathrm{Bi}_{2} \mathrm{O}_{3}-\mathrm{ZnO}-\mathrm{B}_{2} \mathrm{O}_{3}-\mathrm{SLS}$ glass to develop lead-free radiation shielding glasses and to solve the dark brown of bismuth glass. The melt-quenching method was utilized to fabricate $(\mathrm{x}) \mathrm{BaO}(1-\mathrm{x})\left[0.3 \mathrm{ZnO} 0.2 \mathrm{Bi}_{2} \mathrm{O}_{3} 0.2 \mathrm{~B}_{2} \mathrm{O}_{3} 0.3 \mathrm{SLS}\right.$ (where $\mathrm{x}$ are $0.01,0.02,0.03$, 0.04 , and $0.05 \mathrm{~mol}$ ) at $1200{ }^{\circ} \mathrm{C}$. Soda lime silica glass waste (SLS), which is mostly composed of $74.1 \%$ $\mathrm{SiO}_{2}$, was used to obtain $\mathrm{SiO}_{2}$. The mass attenuation coefficient $\left(\mu_{m}\right)$ was investigated utilizing X-ray fluorescence (XRF) at 16.61, 17.74, 21.17, and $25.27 \mathrm{keV}$ and narrow beam geometry at 59.54, 662, and $1333 \mathrm{keV}$. Moreover, the other parameters related to gamma ray shielding properties such as half-value layer (HVL), mean free path (MFP), and effective atomic number $\left(Z_{e f f}\right)$ were computed depending on $\mu_{m}$ values. The results indicated that HVL and MFP decreased, whereas $\mu_{m}$ increased with an increase in $\mathrm{BaO}$ concentration. According to these results, it can be concluded that $\mathrm{BaO}$ doped in $\mathrm{Bi}_{2} \mathrm{O}_{3}-\mathrm{ZnO}-\mathrm{B}_{2} \mathrm{O}_{3}-\mathrm{SLS}$ glass is a nontoxic, transparent to visible light, and a good shielding material against radiation.
\end{abstract}

Keywords: radiation shielding; mass attenuation coefficient; half-value layer; mean free path; soda lime silica glass waste

\section{Introduction}

Heavy metal oxide glasses such as $\mathrm{PbO}, \mathrm{Bi}_{2} \mathrm{O}_{3}$, and $\mathrm{BaO}$ are considered as one of the desirable shielding materials that are used for radiation protection because they possess a lot of interesting properties that make them suitable for radiation protection, such as high density, transparency to visible light, stability in air and water, high interaction cross-section, high infrared transparency, and good absorption of radiation [1,2]. Research interests in the field of radiation shielding materials have changed to using ecofriendly materials instead of $\mathrm{PbO}$ due to the toxicity of lead $[3,4]$.

Recently, many research groups have classified $\mathrm{Bi}_{2} \mathrm{O}_{3}$ glass as an ideal candidate for radiation protection, and they have confirmed that the ability of $\mathrm{Bi}_{2} \mathrm{O}_{3}$ glass to attenuate photons enhances with the increase in the content of $\mathrm{Bi}_{2} \mathrm{O}_{3}[3,5-7]$.

However, there are few issues with the use of high concentrations of $\mathrm{Bi}_{2} \mathrm{O}_{3}$ in glass, such as the color of the glass becoming dark brown or black and the melting temperature 
increasing [8]. As a result, researchers in the materials sciences and the glasses developers have a technical problem in developing highly high transmission $\mathrm{Bi}_{2} \mathrm{O}_{3}$ glass.

Soda lime silica (SLS) glass is one of the most widely used industrial glass products, accounting for up to $90-95 \%$ of global glass production and is used for flat glass or container wares and windowpanes. However, SLS glass waste needs a long time to decompose in addition to the limited landfill sites. This contributes to the accumulation of glass waste. To solve environmental problems, researchers are interested in reusing glass waste as an alternative source of $\mathrm{SiO}_{2}$. There are several benefits to using SLS glass waste as a source of $\mathrm{SiO}_{2}$. This reduces production costs, in addition to the good optical and mechanical characteristics of SLS glass waste, such as high thermal stability, high transparency, low melting point, and perfect chemical stability [9-11].

The aim of the current study is to prepare glass samples consisting of soda lime silica waste glass that have the ability to attenuate photons' intensity, which can be used as radiation protection, in addition to improving the optical properties by reducing the dark brown or black color of glass samples. Furthermore, SLS glass waste is utilized as a source of silicon dioxide $\left(\mathrm{SiO}_{2}\right)$ to reduce the accumulation of SLS glass waste and also reduce production costs. The mass attenuation coefficient was measured at 16.61, 17.74, 21.17, and $25.27 \mathrm{keV}$ utilizing X-ray fluorescence (XRF) and narrow beam geometry at 59.54, 662, and $1333 \mathrm{keV}$. Moreover, other parameters related to radiation shielding, such as the half-value layer (HVL), mean free path (MFP), the effective atomic number $\left(Z_{e f f}\right)$, and the effective electron density $\left(N_{e f f}\right)$ were tested and reported in this study at photon energies of 59.54, 662, and $1333 \mathrm{keV}$.

\section{Materials and Methods}

\subsection{Glasses Preparation}

In the current study, glass samples with the chemical composition of $(\mathrm{x}) \mathrm{BaO}(1-\mathrm{x})[0.3$ $\mathrm{ZnO} 0.2 \mathrm{Bi}_{2} \mathrm{O}_{3} 0.2 \mathrm{~B}_{2} \mathrm{O}_{3} 0.3 \mathrm{SLS}$ ] (where $\mathrm{x}$ are $0.01,0.02,0.03,0.04$, and $0.05 \mathrm{~mol}$ ) were fabricated using the melt quenching technique. SLS glass waste was used to reuse $\mathrm{SiO}_{2}$ contained in it by cleaning and crushing it into a powder utilizing a mortar and pestle. All chemical components such as $\mathrm{Bi}_{2} \mathrm{O}_{3}, \mathrm{ZnO}, \mathrm{B}_{2} \mathrm{O}_{3}$, SLS, and $\mathrm{BaO}$ were mixed completely for $10 \mathrm{~min}$ in an agate mortar and pestle and transferred to an alumina crucible. After that, the crucible was inserted in the electric furnace to melt at a temperature of $1200{ }^{\circ} \mathrm{C}$ for $1.5 \mathrm{~h}$. The melted mixture was poured immediately into the preheated cylinder brass plate and then annealed for $2 \mathrm{~h}$ at approximately $350^{\circ} \mathrm{C}$ in order to prevent internal mechanical stress and strains. Finally, the glass samples were polished after they had cooled to room temperature. These glasses have a thickness of $6 \mathrm{~mm}$ and were labeled $\mathrm{Ba} 1, \mathrm{Ba} 2, \mathrm{Ba} 3, \mathrm{Ba} 4$, and $\mathrm{Ba} 5$, which correspond to doping levels of $0.01,0.02,0.03,0.04$, and $0.05 \mathrm{~mol} \mathrm{BaO}$ (see Figure 1).

The properties of the crystal structure of the prepared glass samples were tested using a Bruker D8 Advance X-ray diffractometer with $\mathrm{Cu}$ Ka radiation, and the X'Pert HighScore software was utilized. The wavelength of the X-ray tube is $1.54180 \AA$, and it operates at $40 \mathrm{kV}, 40 \mathrm{~mA}$. The diffractograms of the glass samples of one phase are in the range of $10^{\circ} \leq \theta \leq 90^{\circ}$.

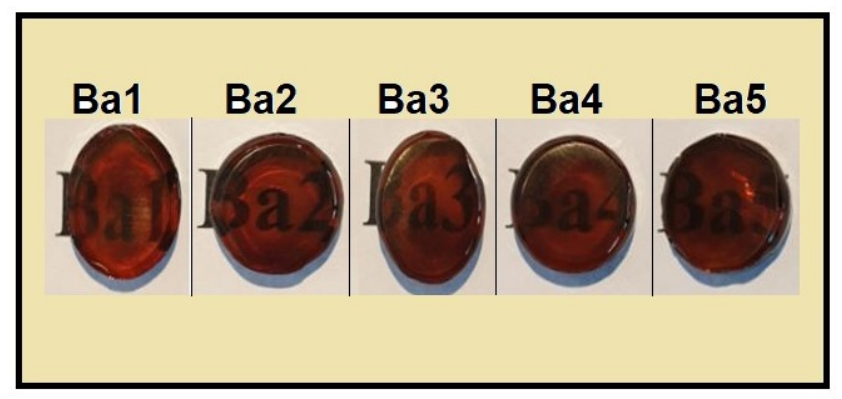

Figure 1. Glass samples of $\mathrm{BaO}$ doped in $\mathrm{Bi}_{2} \mathrm{O}_{3}-\mathrm{ZnO}-\mathrm{B}_{2} \mathrm{O}_{3}$-SLS glass. 


\subsection{Physical Properties}

According to Archimedes' principle, the density of the glass samples $\rho$ is computed utilizing distilled water as the immersion liquid. The following formula was used to compute density [12].

$$
\rho=\frac{W_{a}}{W_{a}-W_{b}} \rho_{\text {distilledwater }}
$$

where $\rho$ indicates glass sample density in $(\mathrm{g}) \mathrm{cm}^{-3}, \rho_{(\text {distilledwater })}$ denotes distilled water density $(1 \mathrm{~g}) \mathrm{cm}^{-3},\left(W_{a}\right)$ denotes the weight $\mathrm{g}$ of the glass sample in air, and $\left(W_{b}\right)$ denotes the weight of the glass sample.

Molar volume was measured using the following formula [13]:

$$
V_{m}=\frac{M_{w t}}{\rho}
$$

where $M_{w t}$ indicates the molecular weight of a substance, and $\rho$ the density of the glass sample.

Oxygen packing density OPD was computed utilizing the following equation [14]:

$$
O P D=1000 \times \frac{c}{V_{m}}
$$

where $c$ denotes the total number of oxygen atoms in the represented composition.

The ion concentration of $\mathrm{Ba}^{+2}(N)$ can be obtained as [15]:

$$
N=\left(\text { mole } \% \circ f B a^{+2}\right) \frac{N_{A} \rho}{M_{w t}}
$$

Polaron radius $\left(r_{p}\right)$, inter-nuclear distance $\left(r_{i}\right)$, and field strength $(F)$ were measured depending on ion concentration by using the following equations [16].

$$
\begin{gathered}
r_{p}=\frac{1}{2}\left(\frac{\pi}{6 N}\right)^{\frac{1}{3}} \\
r_{i}=\left(\frac{1}{N}\right)^{\frac{1}{3}} \\
F=\frac{Z}{r_{p}^{2}}
\end{gathered}
$$

where $N_{A}$ is the Avogadro's number, and $Z$ is the atomic number.

\subsection{Radiation Shielding Features: Theoretical Approach}

The Lambert Beer law was used to compute the experimental mass attenuation coefficient $\mu_{m}$ depending on the following formula [17-19].

$$
\mu_{m}=\frac{\ln \left(\frac{I^{\circ}}{I}\right)}{\rho x}
$$

whereas the theoretical value of $\mu_{m}$ of mixture or compound was measured using the Phy-X/PSD software [20].

$$
\mu_{m}=\sum_{i} w_{i}\left(\mu_{m}\right)_{i}
$$

where $I$ and $I_{\circ}$ indicate the intensity of photons recorded in the detector with and without the glass sample, $\mathrm{x}$ indicates glass thickness, and $w_{i}$ the weight fraction of the component in the compound. The half-value layer (HVL) and mean free path (MFP) are measured using the following equations $[21,22]$ :

$$
H V L=\frac{0.693}{\mu}
$$




$$
M F P=\frac{1}{\mu}
$$

The total atomic cross-section $\sigma_{t, a}$ for materials and electronic cross-section $\sigma_{t, e l}$ were used to calculate effective atomic number $Z_{\text {eff }}$ and electron density $N_{\text {eff }}$ through the following formulas [23,24].

$$
\begin{gathered}
\sigma_{t, a}=\frac{\mu_{m}}{N_{A} \sum_{i} \frac{w_{i}}{A_{i}}} \\
\sigma_{t, e l}=\frac{1}{N_{A}} \sum_{i} \frac{f_{i} A_{i}}{Z_{i}}\left(\mu_{i}\right) \\
Z_{e f f}=\frac{\sigma_{t, a}}{\sigma_{t, e l}} \\
N_{e f f}=\frac{\mu_{m}}{\sigma_{t, e l}}
\end{gathered}
$$

where $A_{i}$ and $N_{A}$ denote the atomic weight and Avogadro's number of the $i$ th element in the composition materials, respectively. $f_{i}$ denotes the number of atoms of element $i$ relative to the total number of atoms of all elements in the composition materials, and $Z_{i}$ is the known atomic number of the $i$ th element in the composition materials.

\section{Radiation Shielding Features: Experimental Approach}

The experimental $\mu_{m}$ of the prepared glass was measured through Equation (8) using $\mathrm{X}$-ray fluorescent equipment (XRF) and narrow beam gamma ray transmission geometry. Figure 2 shows the setup for X-ray fluorescence (XRF). XRF photons were generated through irradiating high-purity metal plates such as Tin (Sn), Palladium (Pd), Molybdenum (Mo), and Niobium $(\mathrm{Nb})$, which are detailed in Table 1 by using $59.54 \mathrm{keV}$ of $100 \mathrm{mCi}$ Am-241. The low-energy germanium (LEGe) detector was used to detect photons that were transmitted through glass samples.

Figure 3 illustrates the setup of the narrow beam geometry. Am-241 of $45 \mu \mathrm{Ci}, \mathrm{Cs}-137$ of $5 \mu \mathrm{Ci}$, and Co-60 of $5 \mu \mathrm{Ci}$ were utilized to measure the $\mu_{m}$ of the glass samples at energies of 59.54, 662, and $1333 \mathrm{keV}$, respectively. The Ludlum detector, composed of a flat-face crystal of thallium-activated sodium iodide (NaI [Tl]), was used to detect photons that passed through the glass samples.

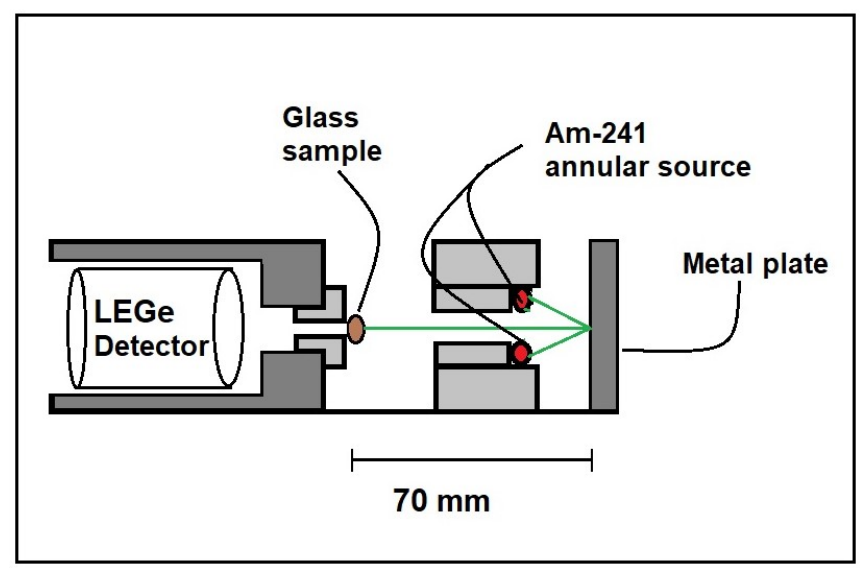

Figure 2. The setup for X-ray fluorescence (XRF). 


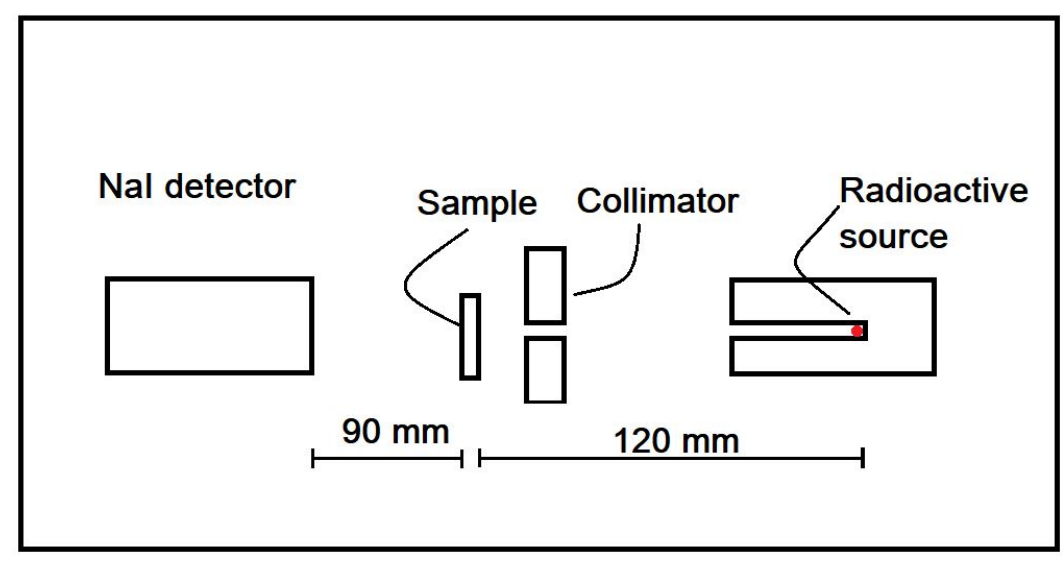

Figure 3. The setup of narrow beam geometry.

Table 1. Metal plates used in X-ray fluorescence (XRF) configuration.

\begin{tabular}{ccccc}
\hline Plate & $\begin{array}{c}\text { Atomic Number } \\
(\mathbf{Z})\end{array}$ & $\begin{array}{c}\text { Thickness } \\
(\mathbf{m m})\end{array}$ & Purity (\%) & $\begin{array}{c}\text { K } \boldsymbol{\alpha} \mathbf{1} \text { Energy } \\
\mathbf{( k e V )}\end{array}$ \\
\hline Niobium $(\mathrm{Nb})$ & 41 & 0.14 & 99.8 & 16.61 \\
Molybdenum $(\mathrm{Mo})$ & 42 & 0.11 & 99.9 & 17.74 \\
Palladium $(\mathrm{Pd})$ & 46 & 0.1 & 99.9 & 21.17 \\
Tin $(\mathrm{Sn})$ & 50 & 0.28 & 99.999 & 25.27 \\
\hline
\end{tabular}

\section{Results and Discussion}

\subsection{Structural Properties}

Figure 4 illustrates the XRD pattern of BaBiZnB-SLS glass samples within the range of $10^{\circ} \leq \theta \leq 90^{\circ}$. It can be seen that all fabricated glasses are amorphous in nature due to the absence of sharp peaks and discrete lines. Furthermore, a broad hump was observed in all fabricated glasses between $25^{\circ}$ and $35^{\circ}$ [25]. The energy-dispersive X-ray (EDX) technique was used to analyze the chemical content of BaBiZnB-SLS glass samples. It can be observed that these glass samples included elements such as oxygen (O), boron (B), silicon ( $\mathrm{Si})$, bismuth $(\mathrm{Bi})$, bismuth $(\mathrm{Zn})$, and barium $(\mathrm{Ba})$, as illustrated in Figure 5 . The chemical compositions of the SLS glass waste was analyzed utilizing energy dispersive X-ray fluorescence at Universiti Sains Malaysia's Centre for Global Archaeological Research. As shown in Figure 6, SLS contains multichemical compounds such as $74.1 \% \mathrm{SiO}_{2}$ as well as other minor elements [26].

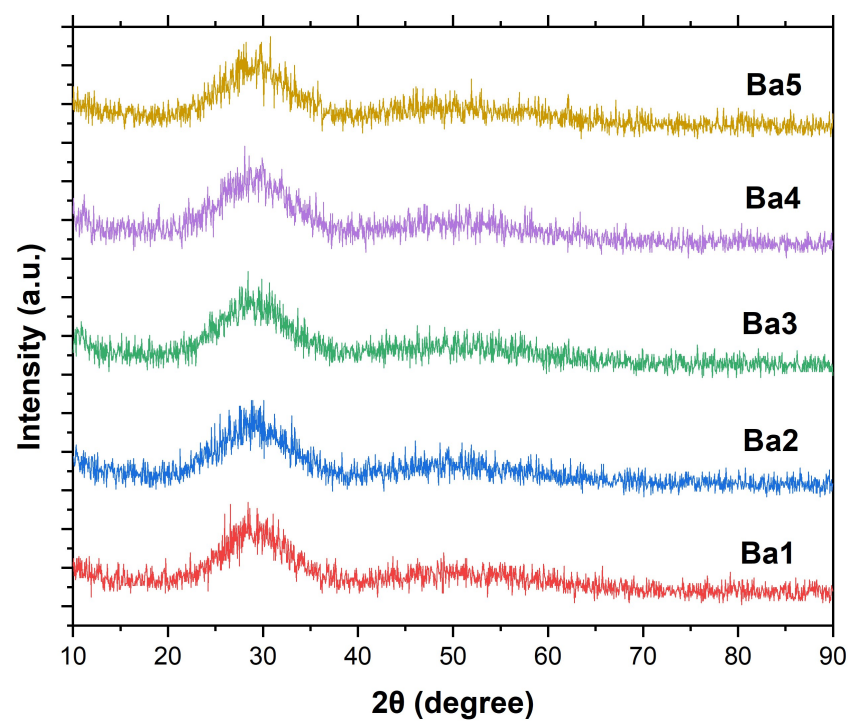

Figure 4. XRD patterns of BaBiZnB-SLS glass samples. 

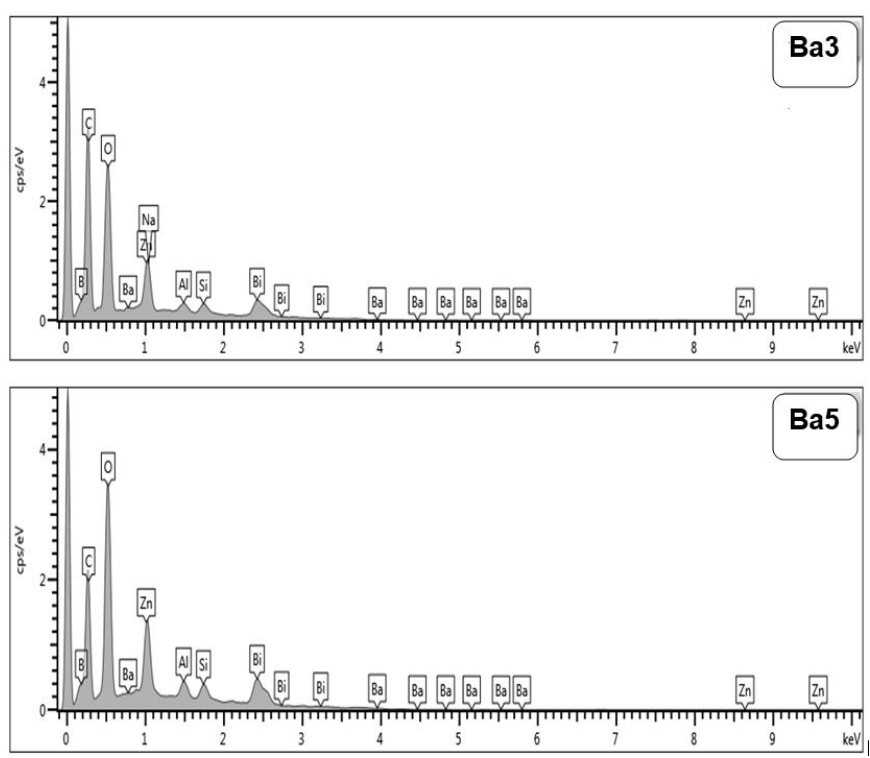

Figure 5. EDX spectra of $\mathrm{Ba} 3$ and $\mathrm{Ba} 5$ glass samples.

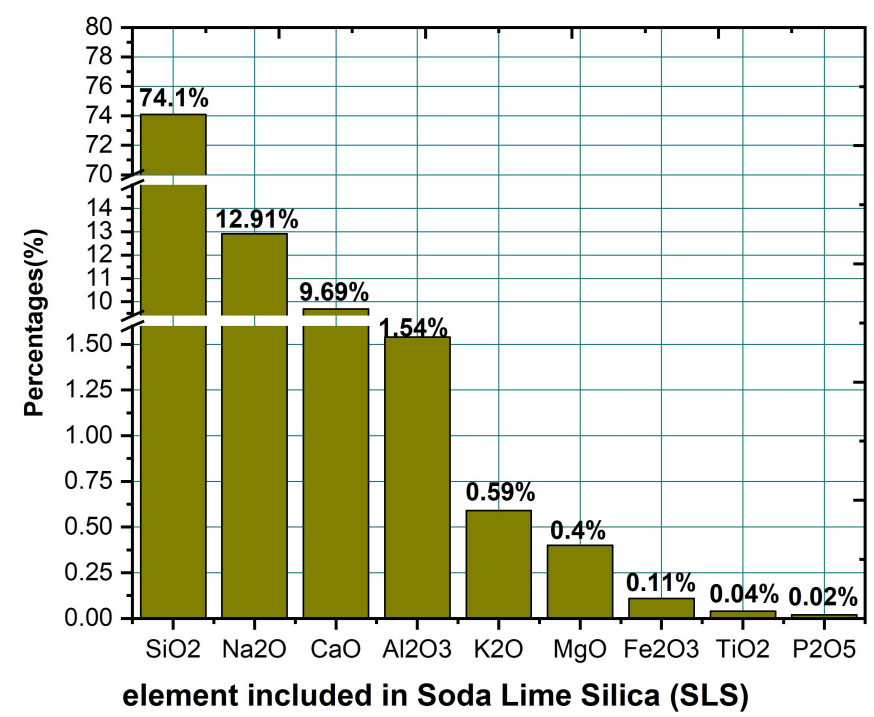

Figure 6. Element included in soda lime silica (SLS).

\subsection{Physical Properties}

The physical characteristics values of BaBiZnB-SLS glass samples were measured and are illustrated in Table 2. Figure 7 clarifies the $\rho$ and $V_{m}$ variation of the prepared glass samples as a function of $\mathrm{BaO}$ mol. It can be seen that the $\rho$ slightly increased from 5.157 to $5.256 \mathrm{~g} \mathrm{~cm}^{-3}$ with increasing $\mathrm{BaO}$ content. The $\rho$ increase is due to the replacement of the $\mathrm{Bi}_{2} \mathrm{O}_{3}-\mathrm{ZnO}-\mathrm{B}_{2} \mathrm{O}_{3}$-SLS (molecular weight are $149.66 \mathrm{~g} \mathrm{~mol}^{-1}$ ) with $\mathrm{BaO}$ (molecular weight is $\left.153.33 \mathrm{~g} \mathrm{~mol}^{-1}\right)$. Furthermore, according to Figure 7, it can be seen that $V_{m}$ values decreased from 29.1 to $28.49 \mathrm{~cm}^{3} / \mathrm{mol}$, indicating resistance to the formation of nonbridging oxygens as well as shrinkage of the glass structure [12,27]. The other physical and structural parameters such as oxygen packing density (OPD), Ba-ion concentration, $r_{i}$, $r_{p}$, and field strength $\mathrm{F}$ of the glass samples were measured to describe $\mathrm{BaO}^{\prime}$ s influence on the BiZnB-SLS glass network. The measured parameters are listed in Table 2 . The result indicates that the OPD, $r_{i}$, and $r_{p}$ decreased with increasing $\mathrm{BaO}$ concentration. On the other hand, Ba-ion concentration and field strength were increased, hence confirming that the glass network has become more compact [28]. 


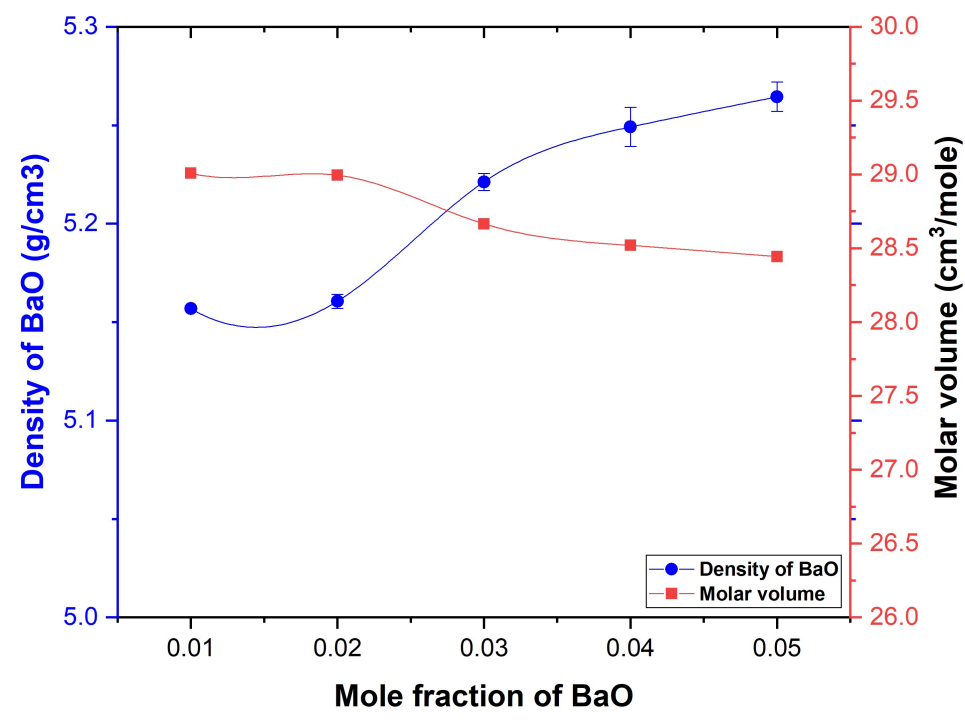

Figure 7. Density and molar volume of BaBiZnB-SLS glasses as a function of the mole fraction.

Table 2. Physical characteristics of BaBiZnB-SLS glass samples.

\begin{tabular}{lccccc}
\hline Measurement & Ba1 & Ba2 & Ba3 & Ba4 & Ba5 \\
\hline Molecular weight $(\mathrm{g})$ & 149.59 & 149.63 & 149.67 & 149.71 & 149.74 \\
Density $\left(\mathrm{g} / \mathrm{cm}^{3}\right)$ & $5.157 \pm 0.001$ & $5.161 \pm 0.004$ & $5.221 \pm 0.004$ & $5.249 \pm 0.001$ & $5.256 \pm 0.01$ \\
Molar volume $\left(\mathrm{cm}^{3} /\right.$ mole) & 29.01 & 28.99 & 28.67 & 28.52 & 28.49 \\
Oxygen packing density, $(\mathrm{g}$-atom/L) & 72.01 & 71.67 & 72.11 & 72.09 & 71.77 \\
Ba-ion concentration $\left(10^{20}\right.$ ion/ $\left.\mathrm{cm}^{3}\right)$ & 2.08 & 4.15 & 6.30 & 8.45 & 10.57 \\
Internuclear distance $(\AA)$ & 16.89 & 13.40 & 11.66 & 10.58 & 9.82 \\
Polaron radius $(\AA)$ & 6.80 & 5.40 & 4.70 & 4.26 & 3.96 \\
Field strength $\left(10^{16} \mathrm{~cm}^{2}\right)$ & 1.21 & 1.92 & 2.54 & 3.08 & 3.58 \\
\hline
\end{tabular}

\subsection{Attenuation of Gamma Rays}

The mass attenuation coefficient of BiZnB-SIS glass doped $\mathrm{BaO}$ was measured utilizing the X-ray fluorescence technique XRF and narrow beam geometry. The experimental $\mu_{m}$ values using XRF for prepared glass were investigated at photon energies of 16.61, 17.74, 21.17, and $25.27 \mathrm{keV}$ and narrow beam geometry at photon energies of $59.54,662$, and $1333 \mathrm{keV}$. The measured $\mu_{m}$ values can be seen in Table 3. It is worth mentioning that the prepared glasses stop almost all the photons with energies of 16.61, 17.74, 21.17, and $25.27 \mathrm{keV}$, and most of the photons cannot reach the detector. The results indicated that the fabricated glass samples have the ability to prevent photons from penetrating glass and reach the detector when photon energy is less than $25.27 \mathrm{keV}$. Figure 8 shows the $\mu_{m}$ of glass samples as a function of $\mathrm{BaO}$ mole fraction. For the energy range from 59.54 to $662 \mathrm{keV}, \mu_{m}$ decreased sharply with gamma energy increasing since the photoelectric effect was dominant in this energy range. However, from 662 to $1333 \mathrm{keV}, \mu_{m}$ decreased slightly with increasing gamma rays, whereas the Compton effect was dominant in this range [7,29]. According to Figure 8 , it can be seen that $\mu_{m}$ was increased with increasing BaO concentration at $59.54 \mathrm{keV}$ due to the utilization of $\mathrm{BaO}$ whose molecular weight is $153.33 \mathrm{~g} / \mathrm{mol}$ as compared to the $\mathrm{Bi}_{2} \mathrm{O}_{3}-\mathrm{ZnO}-\mathrm{B}_{2} \mathrm{O}_{3}$-SLS glasses whose molecular weight is $149.55 \mathrm{~g} / \mathrm{mole}$. However, $\mu_{m}$ values remained approximately constant at 662 and $1333 \mathrm{keV}$ with increasing $\mathrm{BaO}$ concentration. The mass attenuation coefficient at $59.54 \mathrm{keV}$ is higher than at 662 and $1333 \mathrm{keV}$ because the main interaction process at 59.54 is photoelectric [30,31]. The experimental $\mu_{m}$ error was computed depending on the error in transmitted and incident gamma ray intensities, thickness, and density. The calculated error in $\mu_{m}$ values was less than $4 \%$. 
Table 3. The experimental mass attenuation coefficient $\mu_{m}\left(\mathrm{~cm}^{2} \mathrm{~g}^{-1}\right)$ for prepared glass a 59.54, 662, and $1333 \mathrm{keV}$ energy photon.

\begin{tabular}{cccc}
\hline Samples & $\boldsymbol{\mu}_{\boldsymbol{m}}$ at $\mathbf{5 9 . 5 4} \mathbf{~ k e V}$ & $\boldsymbol{\mu}_{\boldsymbol{m}}$ at $\mathbf{6 6 2} \mathbf{~ k e V}$ & $\boldsymbol{\mu}_{\boldsymbol{m}}$ at 1333 keV \\
\hline Ba1 & $2.0011 \pm 0.06$ & $0.0621 \pm 0.005$ & $0.0473 \pm 0.005$ \\
Ba2 & $2.0037 \pm 0.09$ & $0.0624 \pm 0.008$ & $0.0476 \pm 0.007$ \\
Ba3 & $2.0540 \pm 0.08$ & $0.0616 \pm 0.004$ & $0.0469 \pm 0.0054$ \\
Ba4 & $2.0997 \pm 0.05$ & $0.0618 \pm 0.009$ & $0.0471 \pm 0.013$ \\
Ba5 & $2.1248 \pm 0.12$ & $0.0612 \pm 0.007$ & $0.0467 \pm 0.0054$ \\
\hline
\end{tabular}

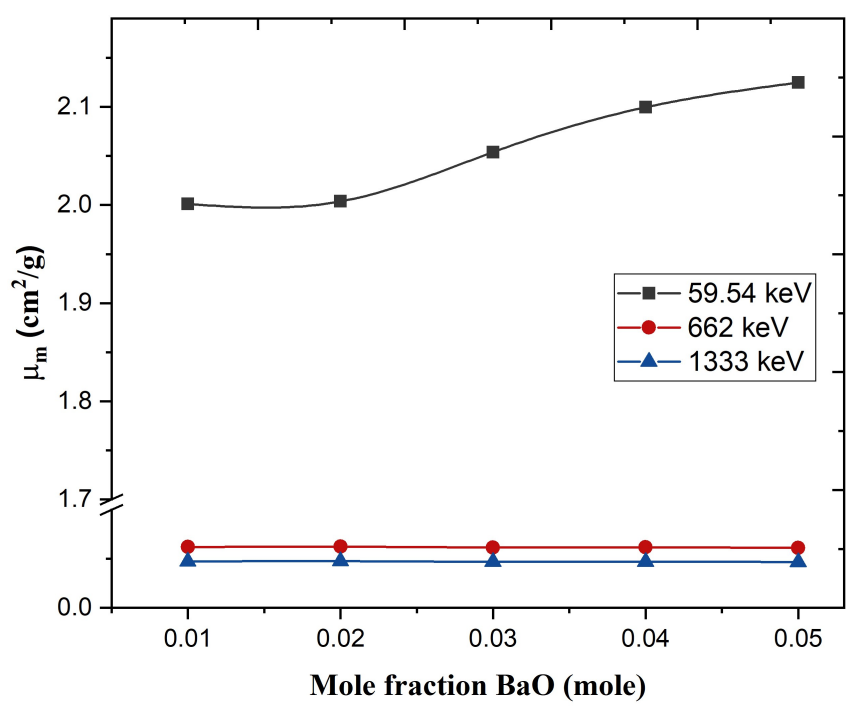

Figure 8. Mass attenuation coefficient of glass samples as a function of the mole fraction.

Numerous shielding characteristics, such as the $N_{\text {eff }}, Z_{e f f}, \mathrm{HVL}$, and MFP, can be calculated using $\mu_{m}$ values as demonstrated in Table 4. According to Table 4 and Figure 9, HVL values increased as gamma energy increased. Furthermore, HVL decreased as $\mathrm{BaO}$ concentration increased. In comparison to Barite concrete at 662 and $1333 \mathrm{keV}$, the current glasses have a lower half-value thickness [27]. Figure 10 illustrates the change in the mean free path of the glasses as a function of the $\mathrm{BaO}$ concentration. MFP values were increased as a result of increased photon energy. In addition, MFP decreased as a result of increased $\mathrm{BaO}$ content. These values have been compared with Ilmenite concrete at 662 and $1333 \mathrm{keV}$. It is observed that BaZnB-SLS glasses have lower MFP values than ilmenite concrete. HVL and MFP results support that current glasses have better shielding properties and can be used as radiation shields [7]. $Z_{e f f}$ and $N_{e f f}$ values are mentioned in Table 4 . It is obvious that the $Z_{e f f}$ and $N_{e f f}$ values of glass samples have decreased with increasing photon energy. As well, $Z_{\text {eff }}$ values increased with increased $\mathrm{BaO}$ content at 662 and $1333 \mathrm{keV}$, while they slightly decreased at $59.54 \mathrm{keV}$. This may be due to the atomic number of barium 56 compared with bismuth 83 . The high atomic number indicates that glasses have powerfully absorbed photons [32].

Table 4. HVL (cm), MFP (cm), $Z_{e f f}$, and $N_{e f f}\left(10^{23}\right)$ (electrons/g) of glass system at 59.54, 662, and $1333 \mathrm{keV}$.

\begin{tabular}{lcccccccccccc}
\hline Sample & $\begin{array}{c}\mathbf{5 9 . 5 4} \mathbf{~ k e V} \\
\text { HVL }\end{array}$ & MFP & $Z_{\text {eff }}$ & $N_{\text {eff }}$ & $\begin{array}{c}\mathbf{6 6 2} \mathbf{k e V} \\
\text { HVL }\end{array}$ & MFP & $Z_{\text {eff }}$ & $N_{\text {eff }}$ & $\begin{array}{c}\text { 1333 keV } \\
\text { HVL }\end{array}$ & MFP & $Z_{\text {eff }}$ & $N_{\text {eff }}$ \\
\hline Ba1 & 0.0672 & 0.0969 & 63.66 & 8.808 & 2.1643 & 3.1230 & 24.30 & 3.405 & 2.8389 & 4.0966 & 20.83 & 2.9019 \\
Ba2 & 0.0670 & 0.0967 & 63.43 & 8.616 & 2.1523 & 3.1057 & 24.37 & 3.405 & 2.8210 & 4.0707 & 20.90 & 2.9018 \\
Ba3 & 0.0646 & 0.0932 & 63.20 & 8.431 & 2.1549 & 3.1096 & 24.43 & 3.405 & 2.8299 & 4.0836 & 20.98 & 2.9017 \\
Ba4 & 0.0629 & 0.0907 & 62.98 & 8.252 & 2.1378 & 3.0848 & 24.49 & 3.405 & 2.8033 & 4.0452 & 21.05 & 2.9015 \\
Ba5 & 0.0621 & 0.0896 & 62.77 & 8.079 & 2.1549 & 3.1096 & 24.55 & 3.404 & 2.8210 & 4.0707 & 21.12 & 2.9014 \\
\hline
\end{tabular}




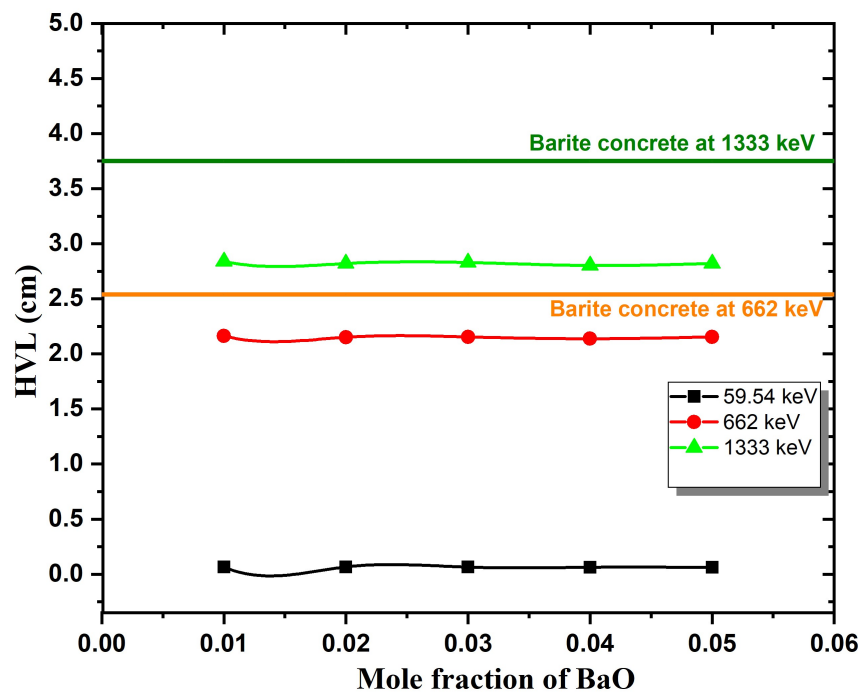

Figure 9. HVL of BaZnB-SLS glasses as a function of the mole fraction.

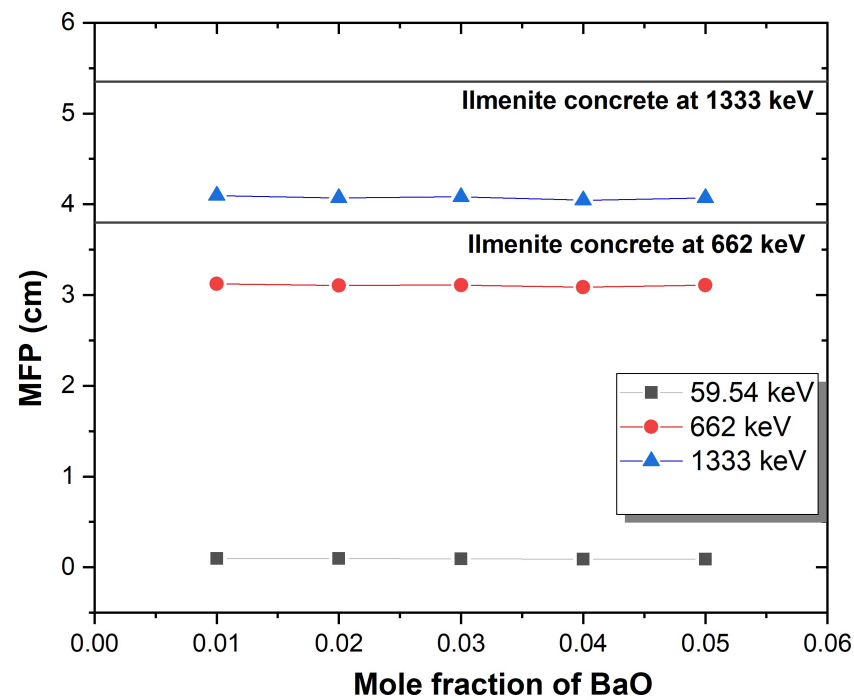

Figure 10. MFP of BaZnB-SLS glasses as a function of the mole fraction.

\section{Conclusions}

The glass systems $(\mathrm{x}) \mathrm{BaO}(1-\mathrm{x})\left[0.3 \mathrm{ZnO} 0.2 \mathrm{Bi}_{2} \mathrm{O}_{3} 0.2 \mathrm{~B}_{2} \mathrm{O}_{3} 0.3 \mathrm{SLS}\right.$ (where $\mathrm{x}$ are $0.01,0.02,0.03,0.04$, and $0.05 \mathrm{~mol}$ ) were fabricated by using the melt quenching method to be used as a radiation shield and have demonstrated to be a suitable gamma ray shielding material. XRD results confirmed the amorphous nature of the BaBiZnB-SLS glass samples. The XRF analysis revealed that the SLS glass primary composition is $74.1 \% \mathrm{SiO}_{2} . \mu_{m}$, $\mathrm{HVL}, \mathrm{MFP}, Z_{e f f}$, and $N_{e f f}$ were examined. The results showed that glass density and $\mu_{m}$ increased and $\mathrm{HVL}$ and MFP decreased with an increase in $\mathrm{BaO}$ concentration in the glass samples. On the other hand, glass samples are capable of absorbing gamma rays with energies less than $25.27 \mathrm{keV}$. The study results confirmed that glass samples can be used to develop a lead-free radiation shielding glass that is effective in the specified energy range. In addition, the glass samples are transparent. 


\begin{abstract}
Author Contributions: T.H.K.: conception of study, data curation formal analysis, methodology, investigation, and writing-review and editing. I.S.M.: conception of study, investigation, funding acquisition, project administration, investigation, and supervision. M.I.S.: formal analysis, investigation, software, and visualization. A.A.R.: funding acquisition, formal analysis, and visualization R.H.: software and validation. M.H.M.Z.: formal analysis, data curation, and resources. M.F.I.A.M.: resources and investigation. N.S.E.: methodology and software. H.S.N.: visualization. N.C.K.: data curation. All authors have read and agreed to the published version of the manuscript.
\end{abstract}

Funding: The authors appreciate the Universiti Sains Malaysia (USM) for the research facilities. Appreciation also goes to the Ministry of Higher Education, Malaysia, for the financial support toward this research under the Fundamental Research Grant Scheme with project code FRGS/1/2019/STG07/ USM/02/19 and project ID 17443 (203/PFIZIK/6711769).

Institutional Review Board Statement: Not applicable.

Informed Consent Statement: Not applicable.

Data Availability Statement: Not applicable.

Conflicts of Interest: The authors declare no conflict of interest.

\title{
References
}

1. Kaur, P.; Singh, D.; Singh, T. Heavy metal oxide glasses as gamma rays shielding material. Nucl. Eng. Des. 2016, 307, 364-376. [CrossRef]

2. Yasaka, P.; Pattanaboonmee, N.; Kim, H.; Limkitjaroenporn, P.; Kaewkhao, J. Gamma radiation shielding and optical properties measurements of zinc bismuth borate glasses. Ann. Nucl. Energy 2014, 68, 4-9. [CrossRef]

3. Cheewasukhanont, W.; Limkitjaroenporn, P.; Kothan, S.; Kedkaew, C.; Kaewkhao, J. The effect of particle size on radiation shielding properties for bismuth borosilicate glass. Radiat. Phys. Chem. 2020, 172, 108791. [CrossRef]

4. Dong, M.; Sayyed, M.; Lakshminarayana, G.; Ersundu, M.Ç.; Ersundu, A.; Nayar, P.; Mahdi, M. Investigation of gamma radiation shielding properties of lithium zinc bismuth borate glasses using XCOM program and MCNP5 code. J. Non-Cryst. Solids 2017, 468, 12-16. [CrossRef]

5. D'Souza, A.N.; Prabhu, N.S.; Sharmila, K.; Sayyed, M.; Somshekarappa, H.; Lakshminarayana, G.; Mandal, S.; Kamath, S.D. Role of $\mathrm{Bi}_{2} \mathrm{O}_{3}$ in altering the structural, optical, mechanical, radiation shielding and thermoluminescence properties of heavy metal oxide borosilicate glasses. J. Non-Cryst. Solids 2020, 542, 120136. [CrossRef]

6. Kurudirek, M.; Chutithanapanon, N.; Laopaiboon, R.; Yenchai, C.; Bootjomchai, C. Effect of $\mathrm{Bi}_{2} \mathrm{O}_{3}$ on gamma ray shielding and structural properties of borosilicate glasses recycled from high pressure sodium lamp glass. J. Alloys Compd. 2018, 745, 355-364. [CrossRef]

7. Bootjomchai, C.; Laopaiboon, J.; Yenchai, C.; Laopaiboon, R. Gamma-ray shielding and structural properties of barium-bismuthborosilicate glasses. Radiat. Phys. Chem. 2012, 81, 785-790. [CrossRef]

8. Sanz, O.; Haro-Poniatowski, E.; Gonzalo, J.; Navarro, J.F. Influence of the melting conditions of heavy metal oxide glasses containing bismuth oxide on their optical absorption. J. Non-Cryst. Solids 2006, 352, 761-768. [CrossRef]

9. Kurtulus, R.; Kavas, T. Investigation on the physical properties, shielding parameters, glass formation ability, and cost analysis for waste soda-lime-silica (SLS) glass containing SrO. Radiat. Phys. Chem. 2020, 176, 109090. [CrossRef]

10. Dong, M.; Xue, X.; Kumar, A.; Yang, H.; Sayyed, M.; Liu, S.; Bu, E. A novel method of utilization of hot dip galvanizing slag using the heat waste from itself for protection from radiation. J. Hazard. Mater. 2018, 344, 602-614. [CrossRef]

11. Almasri, K.A.; Matori, K.A.; Zaid, M.H.M. Effect of sintering temperature on physical, structural and optical properties of wollastonite based glass-ceramic derived from waste soda lime silica glasses. Results Phys. 2017, 7, 2242-2247. [CrossRef]

12. Kumar, A.; Kaur, R.; Sayyed, M.; Rashad, M.; Singh, M.; Ali, A.M. Physical, structural, optical and gamma ray shielding behavior of $(20+x)$ PbO-10 BaO-10 Na $20-10 \mathrm{MgO}-(50-x) \mathrm{B}_{2} \mathrm{O}_{3}$ glasses. Phys. B Condens. Matter 2019, 552, 110-118. [CrossRef]

13. Pawar, P.; Munishwar, S.; Gautam, S.; Gedam, R. Physical, thermal, structural and optical properties of Dy ${ }^{3+}$ doped lithium alumino-borate glasses for bright W-LED. J. Lumin. 2017, 183, 79-88. [CrossRef]

14. Pawar, P.; Munishwar, S.; Gedam, R. Intense white light luminescent Dy ${ }^{3+}$ doped lithium borate glasses for W-LED: A correlation between physical, thermal, structural and optical properties. Solid State Sci. 2017, 64, 41-50. [CrossRef]

15. Ichoja, A.; Hashim, S.; Ghoshal, S.; Hashim, I.; Omar, R. Physical, structural and optical studies on magnesium borate glasses doped with dysprosium ion. J. Rare Earths 2018, 36, 1264-1271. [CrossRef]

16. Mhareb, M.; Hashim, S.; Ghoshal, S.; Alajerami, Y.; Bqoor, M.; Hamdan, A.; Saleh, M.; Karim, M.A. Effect of Dy ${ }_{2} \mathrm{O}_{3}$ impurities on the physical, optical and thermoluminescence properties of lithium borate glass. J. Lumin. 2016, 177, 366-372. [CrossRef]

17. Dong, M.; Xue, X.; Liu, S.; Yang, H.; Li, Z.; Sayyed, M.; Agar, O. Using iron concentrate in Liaoning Province, China, to prepare material for X-Ray shielding. J. Clean. Prod. 2019, 210, 653-659. [CrossRef]

18. Dong, M.; Xue, X.; Yang, H.; Liu, D.; Wang, C.; Li, Z. A novel comprehensive utilization of vanadium slag: As gamma ray shielding material. J. Hazard. Mater. 2016, 318, 751-757. [CrossRef] [PubMed] 
19. Issa, S.A. Effective atomic number and mass attenuation coefficient of $\mathrm{PbO}-\mathrm{BaO}-\mathrm{B}_{2} \mathrm{O}_{3}$ glass system. Radiat. Phys. Chem. 2016, 120, 33-37. [CrossRef]

20. Şakar, E.; Özpolat, Ö.F.; Alım, B.; Sayyed, M.; Kurudirek, M. Phy-X/PSD: Development of a user friendly online software for calculation of parameters relevant to radiation shielding and dosimetry. Radiat. Phys. Chem. 2020, 166, 108496. [CrossRef]

21. Dong, M.; Zhou, S.; Xue, X.; Feng, X.; Sayyed, M.; Khandaker, M.U.; Bradley, D. The potential use of boron containing resources for protection against nuclear radiation. Radiat. Phys. Chem. 2021, 188, 109601. [CrossRef]

22. Sayyed, M.; Elmahroug, Y.; Elbashir, B.; Issa, S.A. Gamma-ray shielding properties of zinc oxide soda lime silica glasses. J. Mater. Sci. Mater. Electron. 2017, 28, 4064-4074. [CrossRef]

23. Kavaz, E.; Tekin, H.; Yorgun, N.Y.; Özdemir, Ö.; Sayyed, M. Structural and nuclear radiation shielding properties of bauxite ore doped lithium borate glasses: Experimental and Monte Carlo study. Radiat. Phys. Chem. 2019, 162, 187-193. [CrossRef]

24. Chanthima, N.; Kaewkhao, J.; Limkitjaroenporn, P.; Tuscharoen, S.; Kothan, S.; Tungjai, M.; Kaewjaeng, S.; Sarachai, S.; Limsuwan, P. Development of $\mathrm{BaO}-\mathrm{ZnO}-\mathrm{B}_{2} \mathrm{O}_{3}$ glasses as a radiation shielding material. Radiat. Phys. Chem. 2017, 137, 72-77. [CrossRef]

25. Barbi, S.; Mugoni, C.; Montorsi, M.; Affatigato, M.; Gatto, C.; Siligardi, C. Structural and optical properties of cerium oxide doped barium bismuth borate glasses. J. Non-Cryst. Solids 2018, 499, 183-188. [CrossRef]

26. Kurtulus, R.; Kavas, T.; Akkurt, I.; Gunoglu, K. An experimental study and WinXCom calculations on X-ray photon characteristics of $\mathrm{Bi}_{2} \mathrm{O}_{3}$-and $\mathrm{Sb}_{2} \mathrm{O}_{3}$-added waste soda-lime-silica glass. Ceram. Int. 2020, 46, 21120-21127. [CrossRef]

27. Kaur, K.; Singh, K.; Anand, V. Correlation of gamma ray shielding and structural properties of $\mathrm{PbO}-\mathrm{BaO}-\mathrm{P}_{2} \mathrm{O}_{5}$ glass system. Nucl. Eng. Des. 2015, 285, 31-38. [CrossRef]

28. Saeed, A.; Elbashar, Y.; El Khameesy, S. A novel barium borate glasses for optical applications. Silicon 2018, 10, 569-574. [CrossRef]

29. Waly, E.S.A.; Fusco, M.A.; Bourham, M.A. Gamma-ray mass attenuation coefficient and half value layer factor of some oxide glass shielding materials. Ann. Nucl. Energy 2016, 96, 26-30. [CrossRef]

30. Kaewkhao, J.; Limsuwan, P. Mass attenuation coefficients and effective atomic numbers in phosphate glass containing $\mathrm{Bi}_{2} \mathrm{O}_{3}$, $\mathrm{PbO}$ and $\mathrm{BaO}$ at $662 \mathrm{keV}$. Nucl. Instrum. Methods Phys. Res. Sect. A Accel. Spectrom. Detect. Assoc. Equip. 2010, 619, $295-297$. [CrossRef]

31. Chanthima, N.; Kaewkhao, J.; Kedkaew, C.; Chewpraditkul, W.; Pokaipisit, A.; Limsuwan, P. Study on interaction of Bi ${ }_{2} \mathrm{O}_{3}, \mathrm{PbO}$ and $\mathrm{BaO}$ in silicate glass system at $662 \mathrm{keV}$ for development of gamma-rays shielding materials. Prog. Nucl. Sci. Technol. 2011, 1, 106-109. [CrossRef]

32. Bagheri, R.; Adeli, R. Gamma-ray shielding properties of phosphate glasses containing $\mathrm{Bi}_{2} \mathrm{O}_{3}, \mathrm{PbO}$, and $\mathrm{BaO}$ in different rates. Radiat. Phys. Chem. 2020, 174, 108918. [CrossRef] 